\title{
Ensino Médio na Rede Federal e nas Redes Estaduais: por que os estudantes alcançam resultados diferentes nas avaliações de larga escala?
}

\author{
Marise N. Ramos* \\ Escola Politécnica de Saúde Joaquim Venâncio/Fiocruz e Universidade do Estado do Rio de Janeiro \\ ramosmn@gmail.com
}

Submetido 22/02/2018 - Aceito 06/03/2018

DOI: $10.15628 /$ holos.2018.6976

\section{RESUMO}

O artigo analisa a política de avaliação em larga escala da educação básica no Brasil, problematizando a diferença de desempenho de estudantes das redes públicas e privadas, e no interior da primeira, com destaque para a rede federal de educação profissional e tecnológica. O curso da análise segue três eixos. O primeiro situa as políticas de avaliação educacional em larga escala face às influências da globalização na educação em nosso país, reconhecendo que, mesmo não perdendo por completo sua autonomia, os estados nacionais de capitalismo dependente se alinham às tendências internacionais. O segundo eixo discute tais avaliações no Ensino Médio, apresentando dados sobre quem são os participantes do Enem, com o intuito de verificar possíveis determinações socioeconômicas dos respectivos desempenhos. Finalmente, demonstra alguns parâmetros de qualidade do ensino que podem explicar as diferenças de desempenhos, confrontandoos com metas e estratégias do Plano Nacional de Educação que visam a melhoria dessa qualidade. Verifica-se o quanto a política educacional está subordinada às avaliações de larga escala e conclui-se sobre a possível inviabilidade de mudanças significativas desse quadro face ao novo regime fiscal instituído pela Emenda Constitucional n. 95/2016.

PALAVRAS-CHAVE: avaliações em larga escala, Exame Nacional do Ensino Médio, qualidade da educação básica, Plano Nacional de Educação.

\section{High School in the Federal Network and State Networks: Why do students achieve different results in large-scale assessments?}

\section{ABSTRACT}

The article analyzes the policy of large-scale evaluation of basic education that takes place in Brazil, problematizing the difference of performance between public and privates instituições, and into the public one, with emphasis on the federal network of professional and technological education. The course of analysis follows three axes. The first one place the large-scale educational evaluation policies in the face of the influences of globalization on education in our country, recognizing that national states of dependent capitalism, while not losing their autonomy completely, are aligned with international trends. The second axes discusses
\end{abstract}

such evaluations in High School, presenting data about who are the participants of Enem, in order to verify the socioeconomic determinations of performances. Finally, we show some parameters of the education quality that can explain the difference in performance, confronting them with goals and strategies of the National Education Pan that focuses best education quality. It is verified that the educational policy is subordinated to the largescale evaluations and it concludes on about the inviability of changes, due the new fiscal regime established by the Constitutional Amendment $n$. 95/2016.

KEYWORDS: large-scale assessments, National Examination of High School, quality of basic education, National Education Plan. 


\section{APRESENTAÇÃO}

Iniciamos nossa exposição situando as políticas de avaliação educacional em larga escala como uma expressão de influências da globalização na educação em nosso país. Compreendemos que, por mais que tais influências não sejam absolutas e lineares, posto que os Estados nacionais não perdem completamente sua autonomia, trata-se de uma tendência internacional de padronização de desempenhos dissociada dos fundamentos da política educacional como responsabilidade do Estado.

Em seguida, discorremos sobre o histórico de implementação das políticas de avaliação em larga escala no Brasil, com ênfase naquelas que abarcam o Ensino Médio. Nesse sentido, discutimos o quadro básico de resultados da Avaliação Nacional da Educação Básica (Aneb) e do Exame Nacional do Ensino Médio (Enem), constatando, por meio deles, algo que já é sabido. 0 desempenho de estudantes da rede federal tende a ser o mais elevado, seguido pela rede privada. As redes públicas municipais e estaduais, em especial esta última, têm resultados abaixo da média nacional. Em relação ao Enem, consideramos importante discutir algumas de suas características, as quais nos parecem mostrar que os determinantes de bons resultados são, também, externos à escola, dado o perfil daqueles que fazem o exame. Uma análise precisa dependeria de obtenção, cruzamento e análise de dados sócioeconômicos dos estudantes das respectivas redes que participam do exame, o que escapa ao escopo da presente abordagem. Em relação à Aneb, seria necessário analisar não somente esses dados, mas os contextuais internos às escolas, desafio igualmente além do que nos propomos neste texto.

Finalmente, problematizamos as diferenças a partir de parâmetros clássicos, tomando como base um estudo com mesmo tema, a fim de demonstrar que o proposto pelas avaliações em larga escala não faz sentido se tais parâmetros não forem prioridade da política educacional. Em síntese, diríamos que, enquanto se priorizam as políticas de avaliação em larga escala, se negligencia o que é fundamental, isto é, a própria política pública de educação básica. Ao mesmo tempo, vemos o quanto metas e estratégias do atual Plano Nacional de Educação voltadas para a elevação da qualidade da educação básica são também fortemente marcadas por princípios da avaliação, subjugando-se os determinantes sociais e das políticas educacionais necessários de serem enfrentados em direção a esse propósito.

\section{AVALIAÇÕES EDUCACIONAIS DE LARGA ESCALA: UM FENÔMENO INTERNACIONAL}

Como avaliações em larga escala são reconhecidas aquelas que visam à avaliação do desempenho escolar, como o nome diz, em larga escala e com caráter sistêmico, realizadas por agentes externos à escola. Nesses termos, a avaliação dos estudantes transcendeu a avaliação da aprendizagem realizada pelo professor como parte do seu fazer pedagógico, de modo que a avaliação em larga escala é que passou a ser determinante de políticas educacionais, com ênfase mais nos resultados do que no processo pedagógico.

Oficialmente se alega que "os dados apresentados visam servir de subsídio para diagnóstico, reflexão e planejamento do trabalho pedagógico da escola, bem como para a 
formulação de ações e políticas públicas com vistas à melhoria da qualidade da educação básica", tendo como foco a qualidade, a equidade e a eficiência da educação básica brasileira ${ }^{1}$. Não obstante, conforme demonstra Werle (2011), tais avaliações tomam o sentido de modernização, racionalidade e eficácia, assentadas no princípio da monoracionalidade, que se impõe de forma independente dos contextos institucionais e organizacionais". (LIMA; AFONSO, 2002, p. 23, apud WERLE, 2011, P. 771)

Do nosso ponto de vista, as políticas de avaliação em larga escala no Brasil fazem parte do conjunto de questões que poderiam ser analisadas na perspectiva da influência de fatores globais sobre políticas nacionais, bem como sobre a natureza e a extensão dessa influência. As influências se manifestam no alinhamento com políticas internacionais equivalentes, como é o caso do Programa Internacional de Avaliação de Estudantes (PISA) e pelos mecanismos de diálogo e assessoramento de organismos internacionais. Trata-se de uma prova de que a capacidade de elaboração e de decisão dos Estados nacionais diminui fortemente, mesmo que não se possa negligenciar o quanto seus representantes atuam como sujeitos nesse processo. Acompanhamos, então, a análise de Dale (2007, apud RODRIGUES, 2017, p. 98), sobre a relação entre globalização e os Estados nacionais, ao considerar que:

(i) Os Estados-nação possuem capacidade de reação frente às mudanças, porém, mesmo mantendo suas soberanias nacionais, perderam, em maior ou menor grau, sua capacidade de formulação de políticas nacionais de forma independente; (ii) a globalização caracteriza-se pela criação de padrões de mudança gerais e abrangentes que, ao serem trabalhados pelos diferentes Estados, acabam moldando respostas similares; e (iii) os efeitos da globalização sobre os serviços públicos são em grande parte indiretos, mediados através da atuação do poder discricionário e da capacidade de direção dos Estados-nação. Portanto, mesmo com o estabelecimento de um novo conjunto de regras pela globalização, 'não existe razão para esperar que todos os países interpretem essas regras de forma idêntica, ou espetar que eles joguem com as regras da mesma forma'”.

Face ao exposto, cabe analisar como o brasil segue a tendência global de realização de avaliações educacionais em larga escala, inclusive, como dissemos, pelo fato de essas extrapolarem o território nacional ao se tornarem avaliações internacionais.

\subsection{As avaliações de larga escala da educação básica no Brasil}

Como nos explica Werle (2011), o ano de 1995 é um marco desta política no Brasil, quando o Sistema de Avaliação da Educação Básica (Saeb) é instituído com apoio financeiro do Banco Mundial (BM). A partir desta data também o papel do INEP começa a se reconfigurar, ao se tornar o órgão centralizador do sistema, com a função de definir objetivos gerais da avaliação, mas terceirizando as operações técnicas. Nesses termos, os professores da Universidade passam a ter posição subalterna, enquanto "as administrações locais veem reduzida sua ação ao simples apoio logístico na fase de aplicação das provas" (WERLE, 2011, 775). Ao mesmo tempo, tal política se capilariza para os sistemas de ensino, os quais passam a instituir seus sistemas estaduais e locais de avaliação nos mesmos moldes, seja para recuperar algum controle sobre seu funcionamento, seja para se prepararem para as avaliações nacionais e internacionais. 
O Saeb é uma avaliação amostral de 4a e 8a séries (5‥ ao 9‥ Ano) do Ensino Fundamental e de 3o ano do Ensino Médio, envolvendo estudantes das redes públicas e privada, de zonas urbanas e rurais, oferecendo informações passíveis de serem tratadas por localização rural ou urbana, por dependência administrativa, por unidade da federação, por região e na totalidade do país. Em 2005 é criada a Prova Brasil - Avaliação Nacional do Rendimento Escolar - de caráter censitário, aplicada de dois em dois anos, para avaliar habilidades de leitura e matemática, assim como o Saeb, mas abrangendo todos os alunos daquele período escolar, de escolas públicas de zonas urbanas, com turmas de 20 alunos ou mais. Em tese, ela "expande o alcance dos resultados oferecidos pelo Saeb" ${ }^{2}$, com a vantagem de apresentar informações que discriminam os resultados para cada município e cada escola participante.

\footnotetext{
Seu objetivo principal é mensurar a qualidade do ensino ministrado nas escolas das redes públicas, produzindo informações sobre os níveis de aprendizagem em Língua Portuguesa (leitura) e em Matemática e fornecendo resultados para cada unidade escolar participante, bem como para as redes de ensino em geral. Apresenta, ainda, indicadores contextuais sobre as condições extra e intraescolares em que ocorre o trabalho da escola ${ }^{3}$.
}

Juntamente com a Prova Brasil, a reestruturação do Saeb em 2005 incluiu a Aneb (Avaliação Nacional da Educação Básica) utilizando os mesmos instrumentos da Prova Brasil e com a mesma periodicidade, porém abrangendo, de forma amostral, escolas e alunos das redes públicas e privadas do país que não atendem aos critérios de participação da Prova Brasil e que pertencem às etapas finais dos três últimos ciclos da Educação Básica: em áreas urbanas e rurais, 5‥ Ano (4a․ Série) e 9‥ Ano (8a. Série) do Ensino Fundamental e 3ạ. Série do Ensino Médio regular. Segundo o INEP, essa avaliação amostral, em conjunto com a realizada pela Prova Brasil, permite manter as características, os objetivos e os procedimentos da avaliação da educação básica efetuada até 2003 pelo Saeb, tendo como foco avaliar a qualidade, a equidade e a eficiência da educação básica brasileira. Os resultados das etapas e dependências administrativas avaliadas exclusivamente pela Aneb são apresentados por regiões geográficas e unidades da federação. As escolas são selecionadas de forma probabilística (por sorteio), considerando os estratos de interesse da avaliação, a saber: dependência administrativa (pública federal, estadual e municipal; privada); Unidade da federação (Estados); localização (urbana e rural); área (capital e interior); porte (pequena: 1 ou 2 turmas; grande: 3 ou mais turmas).

Em 1998, durante o governo de Fernando Henrique Cardozo e tendo Paulo Renato como Ministro da Educação, no contexto do conjunto de reformas implementadas após a aprovação da LDB de 1996, é criado o Exame Nacional do Ensino Médio (Enem), inicialmente com o objetivo de verificar o comportamento de saída de estudantes do ensino médio. Este foi amplamente criticado, inclusive por representar, juntamente com o que foi chamado de Provão, destinado à avaliação do Ensino Superior, mecanismos de diferenciação e de controle de instituições e sistemas de ensino.

No primeiro governo do Presidente Luiz Inácio Lula da Silva, a política de avaliação educacional em larga escala foi rediscutida, considerando, inclusive, a incorporação de intelectuais de universidades na direção do INEP. Nesse âmbito, a avaliação do Ensino Superior se reconfigurou na forma do Exame Nacional de Desempenho de Estudantes (Enade), enquanto o Enem ampliou seus objetivos para servir de mecanismo de ingresso ao ensino superior. Isto convergiu com a criação do Sistema de Seleção Unificada (Sisu), um mecanismo informatizado e 
centralizado de oferta de vagas por Instituições de Ensino Superior públicas a participantes do Enem, o que ajudou a configurar um sistema nacional de Ensino Superior público.

\section{AS AVALIAÇÕES DE LARGA ESCALA NO ENSINO MÉDIO E OS PARTICIPANTES DO ENEM}

Tomando por base os resultados da Aneb 2015, consideramos os resultados das proficiências médias do Brasil em Língua Portuguesa e Matemática do Ensino Médio. Sendo esta equivalente a 267 (total federal, estadual, municipal e privada), temos a média da rede privada e a da rede federal (totalizamos rural e urbana, capital e interior) superiores à média total (309 da privada e 340 da federal), enquanto as redes estadual e municipal ficam abaixo da média (respectivamente 259 e 260$)^{4}$.

Quanto ao Enem, tomando como fonte o relatório pedagógico (INEP, 2015) relativo aos anos 2011 e 2012, algumas informações são significativas.

Em termos regionais, vê-se que a região Sudeste é a que mais participa do Enem (36,6\%), seguida da Nordeste (31,8\%), sendo que o índice de participação de alunos do sudeste é o maior em todas as condições (Ensino Médio concluído, a ser concluído no ano de aplicação, concluído após o ano de aplicação, não concluído e ausência de vínculo escolar - respectivamente, 34,3\%; $41,5 \% ; 34,3 \%, 35,4 \%)$. A região Nordeste apresenta um índice pouco maior na condição de Ensino Médio a ser concluído após o ano de aplicação $(35,7 \%)^{5}$.

Pode-se resumir o perfil dos participantes como se segue ${ }^{6}$ :

a) $55,1 \%$ apresentam 3 anos de conclusão do Ensino Médio, seguido de 28,2\% de não concluintes.

b) $\quad 62,6 \%$ em 2011 e 63,5\% em 2012 possuem residência própria e quitada.

c) $89,7 \%$ em 2011 e 89,3\% em 2012 residem em área urbana.

d) A maioria reside com mais 2 a 4 outros residentes (número de residentes: 2011 $3 / 21,9 \%$; 4/31,9\%; 5/19,0\%. 2012 - 3/22,7\%; 4/33,2\%; 5/19,2\%), o que indica provavelmente famílias com casal de responsáveis com um a três filhos.

e) A princípio, o perfil econômico configurado pela posse de bens é médio, dado que os maiores números referem-se à posse de 1 dos bens de uma residência equipada nesse padrão.

Outra informação é sobre a quantidade de participantes que indicam os motivos para participar do Enem, de acordo com o grau de importância atribuída (2012) ${ }^{7}$. Vê-se a seguinte ordem de importância:

1ํ. Ingressar na Educação Superior Pública.

2‥ Conseguir uma bolsa de estudos (Prouni, outras).

3ㅇ. Testar conhecimentos.

4ㅇ. Aumentar a possibilidade de conseguir um emprego.

5․ Participar do Programa de Financiamento Estudantil.

6‥ Progredir no emprego atual. 
Finalmente, verificamos a proficiência média, por área de conhecimento, dos participantes do Enem, segundo as grandes regiões, sexo, cor/raça, situação de conclusão do Ensino Médio e tipo de instituição escolar frequentada no Ensino Médio ${ }^{8}$. Observamos o seguinte:

Em todas as áreas (Ciências da Natureza, Ciências Humanas, Matemática, Linguagens e Códigos, Redação), tem-se a proficiência acima da média os participantes:

a) moradores das regiões Sul e Sudeste;

b) do sexo feminino;

c) da cor branca, seguida da amarela;

d) egresso do Ensino Médio;

e) que cursou o Ensino Médio somente em instituições privadas.

Esses dados se repetem nos anos seguintes, assim como se repete a comparação entre as proficiências das redes de ensino. Tal como ocorre na Aneb, a rede federal tem desempenho superior à média, seguida da rede privada, depois da municipal, tendo as redes estaduais com o menor desempenho.

Em síntese, vemos que o Enem é um exame realizado por estudantes da considerada "classe média" que tem o acesso ao ensino superior público como projeto ou mesmo ao ensino superior privado, mas com subsídio público. Certamente, esses estudantes advêm de famílias que conseguiram suportar financeiramente a educação de seus filhos. Mesmo as famílias dos que estudam na rede federal, gratuita e de qualidade, provavelmente prescindem da complementação da renda familiar obtida com o trabalho de seus filhos. A propósito, este é o perfil histórico de seus estudantes. Suas famílias veem como oportunidades não somente a qualidade do ensino médio gratuito oferecido por esta rede, que as leva a cumprir uma função propedêutica para essa fração da classe trabalhadora, como também a possibilidade de obterem uma profissão que possa suportar tanto os gastos posteriores com o ensino superior, quanto permitir que se o adie frente a alguma adversidade. Essa característica das instituições da rede federal é frequentemente criticada e usada como argumento para as últimas contra-reformas (as realizadas pelo Decreto n. 2.208/1997 e atualmente pela Lei n.13.415/2017) -

No que se refere aos estudantes da rede privada, cremos não se tratar da elite. Antes, poderíamos nos referir a frações médias da classe trabalhadora que não confia nas redes públicas estaduais e não vê a rede federal como seu projeto, em parte por considerar a profissionalização de seus filhos no ensino médio um constrangimento. Arriscaríamos dizer que muitas dessas famílias custeiam os estudos de seus filhos nessas escolas com algum sacrifício.

Dispomo-nos, assim, a problematizar esses resultados. Porém, mais do que os próprios resultados, problematizaríamos os parâmetros que podem explicar tais diferenças.

\section{PROBLEMATIZANDO AS DIFERENÇAS DE DESEMPENHO ENTRE AS REDES DE ENSINO.}

Tomaremos como referência para esta problematização, o estudo de Wiebusch (2012), sobre fatores e ações que contribuíram para que duas escolas investigadas numa pesquisa estivessem entre as cem melhores escolas estaduais do Rio Grande do Sul no Sistema de 
Avaliação do Estado do Rio Grande do Sul (SAERS) de 2007 e 2008. Apesar de o estudo tratar de um sistema de avaliação estadual, realizado nos moldes do Saeb - portanto, restrita às habilidades de Língua Portuguesa e Matemática, enquanto o Enem incorpora também as Ciências Humanas e da Natureza -, os seus achados que nos mobilizaram a tomá-lo como base para a nossa discussão.

Destaca-se, de início, o fato de os entrevistados justificarem o bom êxito das escolas como uma "unanimidade ao afirmarem ser resultado de um trabalho coletivo, em equipe e em parceria de todos os segmentos da escola, principalmente de todos os professores, de todas as disciplinas, não só das de português e de matemática, disciplinas avaliadas no SAERS" (Id. , ibid., p. 3). O estudo, então, destaca os seguintes "fatores" (sic) como responsáveis pelo êxito das escolas:

a) "papel do professor como essencial para a eficácia escolar, por seu envolvimento, empenho, dedicação, seriedade, coerência e responsabilidade, ao lado de um trabalho pedagógico competente e significativo, enriquecido pela variedade de atividades propostas e desenvolvidas em sala de aula" (Id. , ibid., p. 4);

b) influência dos alunos e das turmas - "maturidade, desejo em progredir, em valorizar o aprender, vontade de estudar, o interesse por eles demonstrado na busca de conhecimentos não só dentro como fora da escola" (Id. , ibid., p. 5);

c) integração da escola com a comunidade - "envolvimento espontâneo e assíduo dos pais no acompanhamento da aprendizagem de seus filhos" (Id. , ibid., p. 5);

d) "ambiente de aprendizagem, a infraestrutura física e a estrutura de sala de aula, acrescidos dos recursos didáticos e de multimídia" (Id. , ibid., p. 6);

e) tempo de dedicação aos estudos - "uma das escolas é de tempo integral, em regime de internato. Nela os alunos têm tempo para estudar, com uma vivência maior com os professores, acesso à biblioteca para pesquisar, sala de informática, atividades complementares, por meio de diferentes oficinas" (Id. , ibid., p. 6);

f) tempo de dedicação dos professores - "na outra foi ressaltado o trabalho integral do professor na mesma escola e com a mesma turma, como um dos fatores determinantes, a continuidade do trabalho, conhecimento dos alunos em suas demandas, potencialidades e limitações. Nessa perspectiva, pode-se pensar que a dedicação exclusiva do professor em uma mesma escola constitui-se uma alternativa que contribui para uma educação de excelência" (Id. , ibid., p. 6);

g) ações desenvolvidas em sala de aula - "fazer pedagógico diferenciado que desperta expectativas nos alunos, por meio de atividades diversificadas e significativas, numa abordagem interdisciplinar, privilegiando a leitura, interpretação, produção textual e resolução de situações-problema, entre outras" (Id. , ibid., p. 7);

h) ações de educação continuada - "sempre estiveram presentes nas propostas dessas escolas, mesmo antes da realização das avaliações externas, como a do SAERS, objetivando a qualificação e a atualização dos professores" (Id. , ibid., p. 9).

Destacamos a relevância do estudo ao comprovar questões conhecidas empiricamente. Mas tais parâmetros, por mais que nos remetam ao trabalho interno à escola, não são questões diretamente da escola, mas sim da política educacional e, em parte, da condição social dos estudantes. Essas determinações precisam ser consideradas ante à avaliação. 
Esses parâmetros não são novidade, pois se olharmos a realidade das escolas da rede federal, todos eles tendem a ser contemplados. Há um dado adicional relativo a esta rede que é o fato de seus alunos serem avaliados previamente nos processos de seleção para o ingresso, mesmo que a política de cotas promova mudanças. Porém, o mesmo não ocorre com as escolas das demais redes públicas. Ainda que as escolas objeto desse estudo sejam de uma rede estadual, elas certamente não são exemplares; ao contrário, podem ser tratadas como exceção e, provavelmente por isto, se tornam casos de estudo.

A intenção da análise sobre o Enem anteriormente apresentada foi chamar a atenção para a determinação econômico-social do desempenho dos estudantes, considerando as condições de estudo e de aprendizagem de que dispõem, tanto em termos da dignidade e condições de vida, quanto às condições internas às escolas, questão que acabamos de abordar. Pode-se concluir que os melhores desempenhos normalmente são os dos estudantes que têm melhores condições econômicas e sociais de vida e que estudam em escolas de melhor qualidade quanto aos parâmetros aqui expostos. Se a primeira determinação não pode ser tratada diretamente pela política educacional, o mesmo não procede quando falamos da qualidade das escolas. Cabe, então, discutir as perspectivas dessa política, o que tentaremos fazer apreciando as metas relativas à qualidade da educação básica constantes do Plano Nacional de Educação 2014-2014.

4.1. A qualidade de ensino no atual PNE e sua determinação pelo sistema de avaliação.

O atual PNE traz a elevação da qualidade do ensino como uma meta, a de número 7: "fomentar a qualidade da educação básica em todas as etapas e modalidades, com melhoria do fluxo escolar e da aprendizagem de modo a atingir as seguintes médias nacionais para o Ideb: para o ensino médio, respectivamente em 2015, 2017, 2019 e 2021: 4,3 4,7 5,0 5,2. Lembremos que o IDEB é calculado a partir dos resultados da Prova Brasil e do fluxo escolar indicado pelo censo educacional.

A primeira estratégia é de caráter pedagógico e remete à Base Nacional Comum Curricular, sem dúvida, a ser usada como referência para as avaliações de larga escala. Considerando a redução da carga horária destinada a esta formação promovida pela atual contra-reforma do Ensino Médio (Lei n. 13.415/2017), entende-se que a expectativa da política educacional é a redução da desigualdade dos resultados dos diferentes sistemas que se pauta pelo mínimo. A estratégia 7.2 refere-se novamente ao alcance de níveis suficientes e desejáveis do aprendizado em relação aos "direitos e objetivos de aprendizado" previstos na BNCC (que, na versão atual, foi revista na forma de competências, ajustando-se a nomenclatura a uma tendência já sinalizada em versões anteriores).

Somente a partir da estratégia 7.12 será feita referência às condições que podem proporcionar esse alcance, pois as anteriores continuam enfatizando as avaliações em detrimento de políticas que proporcionem o esperado nessas avaliações. Assim segue até a estratégia 7.36 .

Mesmo que a estratégia 7.5 fale de apoio técnico e financeiro aos Estados e Municípios por meio do Plano de Ações Articuladas voltadas "à melhoria da gestão educacional, à formação de professores e professoras e profissionais de serviços e apoio escolares, à ampliação e ao 
desenvolvimento de recursos pedagógicos e à melhoria e expansão da infraestrutura física da rede escolar", este apoio está vinculado às avaliações.

A estratégia 7.32 volta a falar no incentivo às avaliações realizadas pelos sistemas de ensino e a 7.36 claramente vincula as avaliações ao rankeamento e premiação das escolas aos moldes gerencialistas, mediante o seu propósito de "estabelecer políticas de estímulo às escolas que melhorarem o desempenho no Ideb, de modo a valorizar o mérito do corpo docente, da direção e da comunidade escolar". Em síntese, o que se vê mesmo no PNE é a superposição das avaliações de larga escala à política educacional, comprovando nosso argumento inicial do alinhamento do país às tendências internacionais.

Nesse cenário, as metas 15 e 16 são estratégicas, por tratarem da formação de professores. A primeira, cujo prazo de início seria em 2015, refere-se à "política nacional de formação dos profissionais da educação de que tratam os incisos I, II e III do caput do art. 61 da Lei no 9.394, de 20 de dezembro de 1996", que deveria se realizar em regime de colaboração entre a União, os estados, o Distrito Federal e os municípios, para que todos os professores da educação básica possuam formação específica de nível superior, "obtida em curso de licenciatura na área de conhecimento em que atuam". A outra meta complementa dos professores da educação básica se formem em nível de pós-graduação até 2024 , além da formação continuada nas respectivas áreas de atuação. Se essas metas tratam de uma dimensão da valorização dos professores, as seguintes são explícitas quanto ao salário (meta 17) e ao plano de carreira (meta 18). Preveem elas, respectivamente, a equiparação do rendimento médio dos professores ao dos demais profissionais com escolaridade equivalente em seis anos de vigência do PNE e, em dois anos, os planos de carreira para os(as) profissionais da educação básica e superior pública de todos os sistemas de ensino, sendo que os primeiros teriam como referência o piso salarial nacional profissional, definido em lei.

Sabemos que uma das metas que pode ter grande impacto na qualidade da educação básica é a 20, que trata do investimento de, no mínimo, 7\% do Produto Interno Bruto (PIB) no quinto ano de vigência do PNE e de $10 \%$ ao final do decênio. Sabemos, porém, que o parágrafo 4․ do artigo 5․ do Plano considerou como investimento público também os recursos repassados a instituições privadas por meio de programas governamentais de educação. Como se não bastasse o fato de isto praticamente deixar inalterado o investimento em educação, a aprovação da Emenda Constitucionais 95 em 2016 torna inviável o cumprimento desta meta. Estudo do DIEESE (2016) demonstra que, se a regra do congelamento dos gastos públicos por vinte anos fosse aplicada em 2002, em 2015 a educação teria uma perda acumulada ${ }^{9}$ de mais de $50 \%$. Nesse contexto fica indefinida até mesmo a implementação do Custo Aluno Qualidade Inicial (CAQi - em 2 anos de vigência do PNE) e do Custo Aluno Qualidade (CAQ), prevista pelas estratégias 20.6 e 20.7 - parâmetro para o financiamento da educação de todas etapas e modalidades da educação básica, a partir do cálculo e do acompanhamento regular dos indicadores de gastos educacionais com investimentos em qualificação e remuneração do pessoal docente e dos demais profissionais da educação pública, em aquisição, manutenção, construção e conservação de instalações e equipamentos necessários ao ensino e em aquisição de material didático-escolar, alimentação e transporte escolar" - cuja metodologia de definição sequer foi divulgada pelo Ministério de Educação 
Em síntese, todas essas metas estão ameaçadas pela Emenda Constitucional n. 95/2016, da mesma forma como está a rede federal, pelo menos no que se refere a sua infraestrutura e de manutenção, frente aos cortes orçamentários que estão por vir.

\section{CONSIDERAÇÕES FINAIS}

O estudo aqui apresentado certamente fica aquém daqueles realizados por pesquisadores que se dedicam diretamente ao tema, assim como da profundidade com que se deve analisar os dados disponíveis mediante o que se pode revelar muito mais do que foi apresentado neste texto. Nosso esquema de análise visou situar o quanto as políticas de avaliação em larga escala da educação básica expressam a influência da globalização e do neoliberalismo no campo da educação em nosso país. Ainda que as influências do movimento global do capital e das políticas internacionais, que têm os Organismos Internacionais como seus representantes não destituam completamente os Estados nacionais de sua autonomia, configuram-se ações de alinhamento com seus princípios. No campo da educação brasileira e, em particular, no que se refere às avaliações em larga escala, essas se manifestam com a implantação do Sistema de Avaliação da Educação Básica (SAEB) seguido da sua reorganização na forma da Avaliação Nacional da Educação Básica (ANEB) e da Avaliação Nacional do Rendimento Escolar (ANRESC), conhecida como Prova Brasil, que confluem para IDEB - Índice de Desenvolvimento da Educação Básica; além do Exame Nacional do Ensino Médio (Enem).

Quanto ao Programa Internacional de Avaliação de Estudantes (PISA), coordenado pela Organização para Cooperação e Desenvolvimento Econômico (OCDE), o Brasil, mesmo não sendo membro dessa organização, participa do exame internacional. As proximidades e os diálogos entre o Ministério da Educação, os países membros e a cúpula dirigente demonstram o alinhamento com a lógica comparativa que orienta essa avaliação. Seus resultados têm sido utilizados como argumentos que justificam políticas educacionais pragmáticas como a recente reformulação do Programa Mais Educação ${ }^{10}$ e a atual contra-reforma do Ensino Médio a qual, dentre muitos aspectos já analisados ${ }^{11}$, apregoa a ampliação da carga horária do Ensino Médio visando ao reforço dos estudos de Língua Portuguesa e Matemática, às custas da diminuição da carga horária da formação geral.

A definição da Base Nacional Comum Curricular (BNCC) como referência da formação geral, por sua vez, também é coerente com essa tendência, pois a implementação de um sistema nacional de avaliação exige uma política curricular também de abrangência nacional. Ao se diminuir a carga horária destinada formação geral do Ensino Médio de 2.400 horas, como definido na LDB de 1996, para 1800 horas, tal como determina a Lei n. 13.415/2017, a ser pautada pela BNCC, a qual, por sua vez, também será a referência para as avaliações, conclui-se sobre a possibilidade de se diminuírem a desigualdade de desempenho dos estudantes das diferentes redes aqui analisadas; porém fazendo-o pelo mínimo. Em outras palavras, diminuemse as exigências para se elevar a média de desempenho, ao mesmo tempo em que se busca o reforço na extensão e fragmentação da carga horária de componentes importantes para as avaliações internacionais.

Esses alinhamentos depõem acerca da fragilidade dos países de capitalismo dependente conduzirem sua própria política pública. Como consequência dessa opção, as políticas educacionais têm sido subordinadas às políticas de avaliação em larga escala, como 
demonstramos com a análise das metas e estratégias de elevação da qualidade da educação básica do Plano Nacional de Educação (PNE). Isto se confirma ao vermos que, dentre as trinta e seis estratégias para a implementação da meta 7, a qual versa sobre a qualidade do ensino, onze se referem às avaliações e não a aspectos e ações objetivas necessárias à procurada melhoria.

Essas medidas são, ao mesmo tempo, coerentes com a redução do investimento em educação forjado pela aprovação da Emenda Constitucional n. 95/2016, o que certamente inviabilizará o cumprimento das metas do PNE. Nesse sentido, a manutenção da educação básica em patamares de baixa qualidade redundará inequivocamente em baixo desempenhos nas avaliações de larga escala, reiterando-se as desigualdades entre estudantes das redes públicas e das redes privadas e aquelas identificadas no interior das redes públicas. Abordamos os determinantes internos às escolas da qualidade do ensino e, assim, dos melhores desempenhos. Porém, a política de austeridade implementada pelo novo regime fiscal que congela os gastos públicos por vinte anos invibializará a elevação da qualidade da educação básica pública, em especial a ministrada nas redes estaduais, mas também a própria rede federal, que tem servido como exemplo de êxito nesta esfera.

Mais do que isto, porém, estão ameaçadas até mesmo as condições das famílias cujos filhos têm assegurado os melhores resultados nas avaliações, como é o caso dos estudantes da rede federal e particular, pois, como afirmamos, sem dúvidas, há determinações econômicosociais fundamentais da política educacional; na verdade, o novo regime fiscal traz determinações estruturais que comprometem gravemente qualidade de vida de toda população brasileira. Neste cenário regressivo dos direitos e de ataque violento às conquistas da classe trabalhadora - aquela que depende efetivamente das políticas públicas - dificilmente as avaliações em larga escala serão alteradas. A responsabilidade continuará recaindo sobre os estudantes, os professores e a escola, demonstração inequívoca da ausência do Estado e da dilatação deletéria do mercado que, de fato, selecionará os sobreviventes.

\section{REFERÊNCIAS}

BRASIL. Instituto Nacional de Estudos e Pesquisas Educacionais Anísio Teixeira. Relatório pedagógico: Enem 2011-2012. Brasília, DF : Inep, 2015.

BRASIL. MEC. PDE : Plano de Desenvolvimento da Educação : SAEB : ensino médio : matrizes de referência, tópicos e descritores. Brasília: MEC, SEB; Inep, 2008.

RAMOS, M. N. FRIGOTTO, G. (2016) Medida Provisória 746/2016: a contra-reforma do Ensino Médio no Golpe de Estado de 31 de agosto de 2016. Revista HISTEDBR On-line, v. 70, p. 3048 ,

ROFRIGUES, R. (2017). "NO CAMINHO DO CURUPIRA: o Programa Nacional de Acesso ao Ensino Técnico e Emprego - Pronatec - e as relações público-privadas". Porto Alegre, 2017. Tese de doutorado - Programa de Pós-Graduação em Educação da Universidade Federal do Rio Grande do Sul, 2017.

WERLE, F. (2011). Políticas de avaliação em larga escala na educação básica: do controle de resultados à intervenção nos processos de operacionalização do ensino. Ensaio: aval. pol. públ. Educ., Rio de Janeiro, v. 19, n. 73, p. 769-792 
WIEBUSCH, E. M. Avaliação em larga escala: uma possibilidade para a melhoria da aprendizagem. IX Anped Sul, 2012. Disponível em http://www.ucs.br/etc/conferencias/index.php/anpedsul/9anpedsul/paper/viewFile/1599/ 140. Consulta em 20/07/2017.

\footnotetext{
${ }^{1}$ http://inep.gov.br/educacao-basica/saeb/sobre-a-anresc-prova-brasil-aneb. Consulta em 20/07/2017.

${ }^{2}$ http://www.educacional.com.br/reportagens/prova_brasil/default_imprimir.asp?strTitulo=. Consulta em 20/07/2017.

${ }^{3}$ http://inep.gov.br/educacao-basica/saeb/sobre-a-anresc-prova-brasil-aneb. Consulta em 20/07/2017.

${ }_{4}^{4}$ Microdados Aneb 2015. Disponível em http://portal.inep.gov.br/microdados. Consulta em 20/07/2017.

${ }^{5}$ Inep (2015). Dados da tabela 49.

${ }^{6}$ Inep (2015)Dados das tabelas 56, 57, 58, 59, 60.

${ }^{7}$ Inep (2015). Dados da tabela 62.

${ }^{8}$ Inep (2015). Dados das Tabelas 63 (2011) e 64 (2012).

9 Veja-se a Nota Técnica do Departamento Intersindical de Estatística e Estudos socioeconômicos (DIEESE): PEC 241/2016: o novo regime fiscal e seus possíveis impactos. Setembro de 2016, número 161.

${ }^{10} \mathrm{Em} 10$ de outubro de 2016, o MEC publicou a Portaria Ministerial n. 1.145 para instituir o programa de incentivo à implantação do horário integral. No mesmo dia, por meio da Portaria n. 1.144, também se criou o "Programa Novo Mais Educação", que "visa melhorar a aprendizagem em Língua Portuguesa e Matemática" nessa etapa da educação básica, diz o caput e o respectivo artigo 1ํ., também ampliando a carga horária escolar.

11 Uma análise sobre a contra-reforma do ensino médio que tem por base a Medida Provisória 746/2016 e o respectivo Projeto de Lei de Conversão n. 34/2016 pode ser encontrado em Ramos e Frigotto (2016).
} 